\title{
Original Article \\ UTILIZATION OF PREGNANCY RELATED CARE AMONG FEMALE TEA GARDEN WORKERS
}

\author{
Arifa Islam 1 , Rowshan Ara², Ummul Khair Alam³, Irin Hossain 4 , Saleha Jahan ${ }^{5}$
}

\begin{abstract}
Introduction: Utilization of pregnancy related care have crucial role in the improvement of reproductive health. Though Bangladesh has taking efforts by introducing various women-oriented development programs to limit the maternal mortality and morbidity, these services are poorly available to the deprived group. They are still struggling with their low utilization of pregnancy care.
\end{abstract}

Objective: The study is aimed to find out the state of utilization of pregnancy related care among female tea garden workers.

Materials and Methods: A cross sectional study was carried out from January to December 2017 among 326 purposively selected female workers residing in tea gardens of Sylhet having a baby of 42 days to one year. A pretested semi-structured questionnaire was used for face to face interview to document the information about their antennal care, intranatal care and postnatal care utilization. Data were analyzed by SPSS software.

Results: The utilization of antenatal care was $52 \%$, institutional delivery was $12.3 \%$, had skilled attendant at birth $18.1 \%$ and received postnatal care $16.6 \%$ among the study population. Respondents antenatal care seeking was associated with their age $(\rho=0.003)$, religion $(\rho=0.000)$, literacy level of self $(\rho=0.000)$ and husband $(\rho=0.002)$ and their monthly family income $(\rho=0.014)$. Place of last delivery of respondents was associated with their age $(\rho=0.001)$. Literacy level of respondents $(\rho=0.023)$ and that of their husbands $(\rho=0.019)$ and their monthly family income $(\rho=0.015)$ was also associated with respondent's birth attendant in their last delivery. In this study respondents postnatal care seeking is associated with their husband's literacy level $(\rho=0.010)$ but not associated with their age group $(\rho=0.420)$, religion $(\rho=0.067)$, their own educational status $(\rho=0.370)$, and monthly family income $(\rho=0.361)$. The main barrier that hold back from utilization of these services was lack of knowledge and ignorance followed by poverty.

Conclusion: This study reveals low utilization of pregnancy related care among the tea garden workers. Effective steps should be taken to encourage the proper utilization of pregnancy related care in this community.

JOPSOM 2019; 38(2): 38-45

Key words: Utilization, Pregnancy related care, Female tea garden workers.

1. Study Physician, Projahnmo Research Foundation, Kaliganj field office, Zakiganj, Sylhet.

2. Professor and Head, Dept. of Population Dynamics, National Institute of Preventive and Social Medicine (NIPSOM), Mohakhali, Dhaka-1212.

3. Lecturer, Department of Maternal and Child Health, National Institute of Preventive and Social Medicine (NIPSOM), Mohakhali, Dhaka-1212.

4. Assistant Professor, Department of Occupational and Environmental Health, National Institute of Preventive and Social Medicine (NIPSOM), Mohakhali, Dhaka-1212.

5. Study Physician, RSV study, Projahnmo Research Foundation, Kaliganj, Zakiganj, Sylhet, Bangladesh.

Correspondence:

Dr. Ummul Khair Alam

Moble:01675515367

Email: ummul.hossain@gmail.com 


\section{INTRODUCTION}

Health problems associated to pregnancy or childbirth are more commonly seen in women of developing countries. As there is ridiculous contact to contemporary health services and meager consumption, this state is poorer in evolving countries like Bangladesh. Each year from maternal reasons an estimated 525,000 women dies, nearly all from developing countries [1].

Antenatal care (ANC) is the care which is delivered to a woman during her pregnancy period to ensure optimum health of mother and baby. Over half a million women die as because of pregnancy and childbirth related complications each year.About $90 \%$ of them are of developing countries. To decrease the maternal and child mortality and morbidity proper ANC is a must. Many women in developing countries are not fortunate enough to receive such care. For successful program implementation it is necessary to understand knowledge and practices of the community regarding care during pregnancy and delivery [2].

The clinical basis for availability of skilled care during pregnancy and childbirth is undeniable. Skilled attendants like people with midwifery skills, such as midwives and doctors and nurses who are qualified enough to manage uneventful pregnancies, childbirth and the immediate postnatal period. They identify, manage or refer complicated cases to higher center to confirm the survival and wellbeing of pregnant women and their infants. Health professionals who are working as skilled attendants should be able to detect early signs of complications and provide first line emergency obstetric care (including emergency newborn care) if required [3].The utilization of postnatal healthcare services positively influenced by ANC. As most of the maternal death occur in the first week after delivery, here PNC and intrapartum care have significant role to reduce maternal mortality [4].

In developing countries, about 2,86,000 of maternal death were due to preventable complications [5]. The three delays are the primary cause of maternal death which includes delay in seeking care, delay in reaching health care facility and delay at an institutional level in providing appropriate care [6].

WHO recommends that essential interventions can be provided over four visits at specified intervals, for healthy women with no underlying medical problems. Early identification of underlying conditions is important for many of the essential interventions in ANC. Hence the first ANC visit should be as early as possible in pregnancy, preferably in the first trimester. The last visit should be at around 37 weeks or near the expected date of birth to ensure that appropriate advice and care have been provided to prevent and manage problems such as multiple births (e.g. twins), post maturity (e.g. birth after 42 weeks of pregnancy, which carries an increased risk of fetal death), and abnormal positions of the baby (e.g. breech, where the baby's head is not the presenting part at birth) [7].

A Nepalese study showed factors related with an increased risk of home delivery which includes a remoteness of more than one hour to the maternity hospital, low service score status, low literacy level, multi-parity and antenatal care during pregnancy. In many countries post-natal care utilization is very low. Utilization of post-natal care (PNC) services is interrelated to the level of awareness of the services, women's livelihood, culture, the number of pregnancies and children, and the husbands' socioeconomic status, occupation and education. Women who had never used ANC, were less likely to practice PNC. Women who suffer from health problems are more likely to seek post-natal care. Those who had prior complications during delivery were strongly interested to use PNC compared to those who had an uneventful delivery [8].

In spite of developments, pregnancy-related complications remain the leading cause of death and disability excessively among different Indigenous, non-Indigenous and cultural groups [4]. Tea garden workers have a different identity which is neither urban nor industrial nor rural. Only $30-40 \%$ of tea garden workers are permanent among all of the workers. Almost all of the gardens recruit new labour (also called Faltoo labour) at the time of the topmost season. The new workers receive same salary but they remain deprived of the benefits that the permanent worker get. There is no maternity benefit scheme for the female tea garden workers. The poor socio-economic condition, illiteracy and unhygienic livelihood of the population left them helpless in many ways [9].

The prevalence of utilization of pregnancy related care among female tea garden workers are still far below than acceptable standard. This study will help to estimate the proportion of pregnant tea garden workers utilized pregnancy related care and find out the barriers of utilization of pregnancy related care.

\section{MATERIALS AND METHODS}

The present research was undertaken with the objective to estimate the proportion of pregnant tea garden workers utilized pregnancy related care and find out the barriers of utilization of pregnancy 
related care. It was a one-time question answer session, within a short period of time and the study was a descriptive type of cross sectional study. The study was conducted over a period of 1 year from January to December 2017.The study was carried out in four tea gardens in Sylhet city namely Tarapur tea stare, Ali Bahar tea state, Malnicherra tea state and Khadim tea state. The study was conducted among female tea garden worker willing to participate and having a baby of at least 42 days to one year. Sample size was calculated as 381 considering the prevalence 55\% (Maternal Health Care Service Utilization in Tea Garden of Darjeeling, India 2013) with 95\% confidence interval and $5 \%$ allowable error. For convenience, we limited the sample size of this study to 326 respondents. The respondents were selected by purposive sampling from house to house search. Sampling was continued until the desired respondents were engaged. A semi structured questionnaire was developed in English using the variables according to the specific objectives. The questionnaire was translated into Bangla and it was pretested in another tea state among the female worker with similar characteristics. The questionnaire was then finalized after necessary modification according to the findings of the pretesting. At the beginning of the data collection, permission was taken from each authority of the tea gardens. A pre-tested semi structured questionnaire was used for data collection. The detail of the study was explicitly explained to each eligible respondents and informed written consent from the respondents were obtained. After that data was collected from the respondents through face to face interview privately as much as possible. Questions were asked in Bengali. The respondents were given full assurance on some ethical point of view that under no circumstances any part of the interview will be disclosed to any unauthorized person. After data collection, individual questionnaire was edited through checking and rechecking to see whether it was filled completely and consistently. The data was analyzed by using SPSS version 20. No intervention or any other invasive procedure was undertaken in the study. Formal approval of the study was obtained from Institutional Review Board of NIPSOM.

\section{RESULTS}

Among 326 respondent's majority are in age group $26-30$ years $(122,37.4 \%)$ and here the mean age was 25.84 years $(\mathrm{SD} \pm 4.374)$ with the minimum age is 18 years maximum age is 35 years with a range of 17 years. Most of the study population follow Hindu religion $(79.8 \%)$ rest of them follow Islam (20.2\%). A large number of the respondents are either illiterate $(28.2 \%)$ or can only signature $(29.1 \%)$. Similar literacy level $(20.3 \%$ are illiterate and $40 \%$ can only do signature) found among the husband of the respondents. Maximum respondent's (47.5\%) monthly family income is less than 5000 BDT. Here the mean family income is 7161.96 Taka (SD \pm 4085.354) with the minimum income is 1600Taka maximum income is 30000 Taka with a range of 28400 Taka (Table 1).

Among 326 respondent's majority of respondents $(169,52 \%)$ received ANC and rest of them (157, $48 \%$ ) did not receive ANC during their last pregnancy. Most of the participants $(286,87.7 \%)$ delivered their last child in their own house and only few had institutional delivery (40, 12.3\%). $81.9 \%$ respondent's delivery assistant is unskilled and only $18.1 \%$ delivered with the help of skilled birth attendant. Most of the (83.4\%) female worker under study did not receive PNC after their last delivery (Table 2).

In our study respondent's age, religion, literacy level and their monthly family income was found significantly associated with their ANC seeking behavior (Table 3). Respondent's place of delivery found associated with age (Table 4). Literacy level of respondent, that of their husbands and their monthly family income was positively associated with their birth attendant (Table 5). Respondents PNC seeking was only associated with their husband's literacy level (Table 6). Illiteracy (27.4\%), ignorance (36.3\%) and poverty $(32.5 \%)$ were the common barrier to seek ANC and the main reason of not receiving PNC was lack of proper knowledge about it $(68 \%)$ in the tea garden community (Table 7).

Table 1: Socio-demographic characteristics of the female tea garden workers

\begin{tabular}{|c|c|c|}
\hline Socio-demographic characteristics & Frequency & Percentage \\
\hline Age & 51 & 15.6 \\
\hline $15-20$ & 113 & 34.7 \\
\hline $21-25$ & 122 & 37.4 \\
\hline $26-30$ & 40 & 12.3 \\
\hline $31-35$ &
\end{tabular}




\begin{tabular}{|c|c|c|}
\hline Socio-demographic characteristics & Frequency & Percentage \\
\hline Religion & 66 & 20.2 \\
\hline Muslim & 260 & 79.8 \\
\hline Hindu & 92 & 28.2 \\
\hline Educational qualification of respondent \\
\hline Illiterate & 95 & 29.1 \\
\hline Signature only & 114 & 35 \\
\hline Primary & 21 & 6.4 \\
\hline Secondary & 4 & 1.2 \\
\hline Higher secondary & 64 & 20.3 \\
\hline Education of respondent's husband & 126 & 40.0 \\
\hline Illiterate & 67 & 21.3 \\
\hline Signature only & 52 & 16.5 \\
\hline Primary & 6 & 1.9 \\
\hline Higher secondary & 155 & 47.5 \\
\hline Monthly income (In Taka) & 118 & 36.2 \\
\hline Less than 5000 & 53 & 16.3 \\
\hline 5001-10000 &
\end{tabular}

Table 2: Utilization of pregnancy related care among female workers

\begin{tabular}{ccc}
\hline Pregnancy related care & Frequency & Percentage \\
\hline ANC received by respondents & 169 & 52 \\
ANC not received by respondents & 157 & 48 \\
Delivery by skilled attendant & 59 & 18.1 \\
Delivery by unskilled attendant & 267 & 81.9 \\
Institutional delivery & 40 & 12.3 \\
Home delivery & 286 & 87.7 \\
PNC received by respondents & 54 & 16.6 \\
PNC not received by respondents & 272 & 83.4 \\
\hline
\end{tabular}

Table 3: Antenatal care seeking and socio demographic characteristics of the female workers

\begin{tabular}{|c|c|c|c|}
\hline Socio-demographic characteristics & ANC received & ANC not received & $\begin{array}{c}\boldsymbol{\chi} \mathbf{2} \\
\boldsymbol{\rho} \text {-value }\end{array}$ \\
\hline Age & $108(59.0 \%)$ & $75(41.0 \%)$ & 8.605 \\
\hline $18-26$ & $61(42.7 \%)$ & $82(57.3 \%)$ & 0.003 \\
\hline Religion & $18(27.3 \%)$ & $48(72.7 \%)$ & 20.006 \\
\hline \multicolumn{5}{|c|}{ Muslim } & $151(58.1 \%)$ & $109(41.9 \%)$ & 0.000 \\
\hline
\end{tabular}




\begin{tabular}{|c|c|c|c|}
\hline Socio-demographic characteristics & ANC received & ANC not received & $\begin{array}{c}\chi^{2} \\
\rho \text {-value }\end{array}$ \\
\hline \multicolumn{4}{|l|}{ Education of respondent } \\
\hline Illiterate and signature only & $79(42.2 \%)$ & $108(57.8 \%)$ & 16.171 \\
\hline Primary and above & $90(64.7 \%)$ & $49(35.3 \%)$ & 0.000 \\
\hline \multicolumn{4}{|l|}{ Education of respondent's husband } \\
\hline Illiterate and signature only & $87(45.8 \%)$ & $103(54.2 \%)$ & 9.169 \\
\hline Primary and above & $79(63.2 \%$ & $46(36.8 \%)$ & 0.002 \\
\hline \multicolumn{4}{|l|}{ Monthly family income } \\
\hline Less than 5000 & $31(39.2 \%)$ & $48(60.8 \%)$ & 8.484 \\
\hline $5000-10000$ & $104(53.6 \%)$ & $90(46.4 \%)$ & 0.014 \\
\hline Above 10000 & $34(64.2 \%)$ & $19(35.8 \%)$ & \\
\hline
\end{tabular}

Table 4: Association between socio-demographic characteristics and place of delivery

\begin{tabular}{|c|c|c|c|}
\hline $\begin{array}{l}\text { Socio-demographic } \\
\text { characteristics }\end{array}$ & Home delivery & $\begin{array}{l}\text { Institutional } \\
\text { delivery }\end{array}$ & $\begin{array}{c}\chi^{2} \\
\rho \text {-value }\end{array}$ \\
\hline \multicolumn{4}{|l|}{ Age } \\
\hline $18-26$ & $151(82.5 \%)$ & $32(17.5 \%)$ & 10.546 \\
\hline $27-35$ & $135(94.4 \%)$ & $8(5.6 \%)$ & 0.001 \\
\hline \multicolumn{4}{|l|}{ Religion } \\
\hline Muslim & $61(92.4 \%)$ & $5(7.6 \%)$ & 1.694 \\
\hline Hindu & $225(86.5 \%)$ & $35(13.5 \%)$ & 0.193 \\
\hline \multicolumn{4}{|l|}{ Monthly family income } \\
\hline Less than 5000 & $70(88.6 \%)$ & $9(11.4 \%)$ & 4.294 \\
\hline $5000-10000$ & $174(89.7 \%)$ & $20(10.3 \%)$ & 0.117 \\
\hline Above 10000 & $42(79.2 \%)$ & $11(20.8 \%)$ & \\
\hline
\end{tabular}

Table 5: Association between socio-demographic characteristics of the workers and type of birth attendant

\begin{tabular}{|c|c|c|c|}
\hline Socio-demographic characteristics & $\begin{array}{c}\text { Unskilled birth } \\
\text { attendant }\end{array}$ & $\begin{array}{c}\text { Skilled birth } \\
\text { attendant }\end{array}$ & $\begin{array}{c}\chi^{2} \\
\rho \text {-value }\end{array}$ \\
\hline \multicolumn{4}{|l|}{ Education of respondent } \\
\hline Illiterate and signature only & $161(86.1 \%)$ & $26(13.9 \%)$ & 5.205 \\
\hline Primary and above & $106(76.3 \%)$ & $33(23.7 \%)$ & 0.023 \\
\hline Illiterate and signature only & $164(86.3 \%)$ & $26(13.7 \%)$ & 5.489 \\
\hline Primary and above & $95(76.0 \%)$ & $30(24.0 \%)$ & 0.019 \\
\hline \multicolumn{4}{|l|}{ Monthly family income } \\
\hline Less than 5000 & $67(84.8 \%)$ & $12(15.2 \%)$ & 8.344 \\
\hline $5000-10000$ & $164(84.5 \%)$ & $30(15.5 \%)$ & 0.015 \\
\hline Above 10000 & $36(67.9 \%)$ & $17(32.1 \%)$ & \\
\hline
\end{tabular}


Table 6: Association between postnatal care seeking and socio demographic characteristics of the workers

\begin{tabular}{|c|c|c|c|}
\hline Socio-demographic characteristics & PNC received & PNC not received & $\begin{array}{c}\chi^{2} \\
\rho \text {-value }\end{array}$ \\
\hline \multicolumn{4}{|l|}{ Age } \\
\hline $18-26$ & $33(18.0 \%)$ & $150(82.0 \%)$ & 0.651 \\
\hline $27-35$ & $21(14.7 \%)$ & $122(85.3 \%)$ & 0.420 \\
\hline \multicolumn{4}{|l|}{ Religion } \\
\hline Muslim & $6(9.1 \%)$ & $60(90.9 \%)$ & 3.344 \\
\hline Hindu & $48(18.5 \%)$ & $212(81.5 \%)$ & 0.067 \\
\hline \multicolumn{4}{|l|}{ Literacy of respondent } \\
\hline Illiterate and signature only & $28(15.0 \%)$ & $159(85.0 \%)$ & 0.803 \\
\hline Primary and above & $26(18.7 \%)$ & $113(81.3 \%)$ & 0.370 \\
\hline \multicolumn{4}{|l|}{ Literacy of respondent's husband } \\
\hline Illiterate and signature only & $39(20.5 \%)$ & $151(79.5 \%)$ & 6.634 \\
\hline Primary and above & $12(9.6 \%)$ & $113(90.4 \%)$ & 0.010 \\
\hline \multicolumn{4}{|l|}{ Monthly family income } \\
\hline Less than 5000 & $9(11.4 \%)$ & $70(88.6 \%)$ & 2.039 \\
\hline $5000-10000$ & $35(18.0 \%)$ & $159(82.0 \%)$ & 0.361 \\
\hline Above 10000 & $10(18.9 \%)$ & $43(81.1 \%)$ & \\
\hline
\end{tabular}

Table 7: Distribution of barriers to utilization of pregnancy related care

\begin{tabular}{|c|c|c|}
\hline Barriers & Frequency & Percentage \\
\hline Barriers to seek ANC & 43 & 27.4 \\
\hline Didn't know service was needed & 6 & 3.8 \\
\hline Family didn't allow & 57 & 36.3 \\
\hline Didn't think necessary to go & 51 & 32.5 \\
\hline Lack of money to pay for the service & 187 & 68.8 \\
\hline Barriers to seek PNC & 2 & 0.6 \\
\hline Didn't know service was needed & 61 & 22.4 \\
\hline Family didn't allow & 3 & 0.9 \\
\hline Didn't think necessary to go & 19 & 7.0 \\
\hline Too busy to visit for PNC &
\end{tabular}

\section{DISCUSSION}

The study revealed among the respondents, majority are within the age group 25-30 years where the mean age was 25.84 years with $\mathrm{SD} \pm 4.374$, mostly Hindu $(80 \%)$. Bhattacherjee, S. et al. found maximum respondents resides in the age group of 25-29 years, mostly Hindu (83.6\%) and the findings are similar to that of ours study [10]. A large number of the respondents are either illiterate $(28.2 \%)$ or can only signature (29.1\%) in our study. A study in slum area of Bangladesh found $75 \%$ of women had no formal education [11]. Maximum respondent's husband (74.5\%) was day laborer. Majority of the respondent's monthly family income was TK 5000 to TK 10000. Manna, P.K., et al. conducted a study on a tea garden in India and found that maximum respondents monthly family income was about 2600 taka [12] which is lower than the income of workers 
of Bangladesh. The expansion in GDP of Bangladesh may have a role here.

Only $52 \%$ of respondents received ANC at least once in their last pregnancy, which is lower than the national figure. In Bangladesh Seventy-eight percent of women received antenatal care at least once from a provider and it is 53\% in Sylhet division [13]. Bhattacherjee, S. found $48.6 \%$ of respondents had availed antenatal care in their study [10]. Ansari, M.M.H, et al. stated that $58.4 \%$ of participants received ANC visits at least once [14].

There are several factors which influences the utilization of maternal health care. These factors operate their impact at various levels. In this study we found respondents ANC seeking was associated with their age $(\rho=0.003)$, religion $(\rho=0.000)$, literacy level of self $(\rho=0.000)$ and husband $(\rho=0.002)$, monthly family income $(\rho=0.014)$. Studies found that women who were better educated, had higher incomes had more antenatal care visits than women who were less educated, had lower incomes. Bhattacherjee, S. found there is no significant association between antenatal care utilization and mother's age and religion which is dissimilar to our study [10]. Bhattacherjee, S. also found association with literacy level of women, husband's education and monthly family income that is likely to ours study [10]. Manna, P.K., et al. reported positive association between lower maternal age, Hindu religion, higher education of mother and father and high-income group and antenatal care utilization [12]. Here higher age group, Muslims, illiterate and poor economic group mothers have taken less antenatal care. Several studies from other countries have demonstrated that women's education is the most important determinants of ANC utilization. Similarity to our study, Islam, M.R. and Odland, J.O. found husband's education was significantly associated with an ANC visit [4].

A very alarming finding of the study is, home delivery of most of the respondents $(87.7 \%)$. In national level the figure is $63 \%$ and in Sylhet division it is $77.4 \%$ [13]. Moreover, study reveals $81.9 \%$ delivery was conducted by unskilled birth attendant. According to BDHS 2014, 73\% delivery is conducted by unskilled attendant in Sylhet [13]. Bhattacherjee, S. found $73.5 \%$ of participants in their study had skilled attendant at birth [10] which is nearly opposite to our study. The financial assistance to the backward classes was identified as the reason behind the satisfactory outcome. The socio-economic characters play role in delivery practices of the mother. In this study, place of last delivery of respondents was associated with respondents age
( $\rho=0.001)$ but their religion $(\rho=0.193)$, monthly family income $(\rho=0.117)$ was not associated with place of delivery. In a previous study authors found education of mother, religion, economy was significantly related to the delivery practices of the mothers [12]. They reported that the Muslims, poor economic people do not like to go to health institutions for delivery. Bhattacherjee, S. stated that when institutional delivery was concerned, the age of mother, belonging to Hinduism, their high income had good linkage with delivering at health facility than their counterparts [10]. In our study, literacy level of respondents $(\rho=0.023)$ and that of their husbands $(\rho=0.019)$ and their monthly family income $(\rho=0.015)$ was associated with respondent's birth attendant in their last delivery which is likely to the finding of reviewed literatures.

Last but not least the study explored that the PNC seeking by the respondents (17\%) was very low than the expected proportion. The rest 83\% did not received any PNC services which higher than the nationwide state $(61 \%)$ [13]. The tea garden workers of India were found to receive PNC at $72.6 \%$ which is far better than our finding [10]. In our study respondents PNC seeking is associated with their husband's literacy level but not associated with their age group $(\rho=0.420)$, religion $(\rho=0.067)$, their own educational status $(\rho=0.370)$, monthly family income $(\rho=0.361)$. Bhattacherjee, S. et al. found PNC was significantly associated with maternal age, religion. High income and better educational level of respondent's husband were positively associated with utilization of PNC [10].

The participants who had not utilized the pregnancy care were asked to tell about the cause behind it. Illiteracy $(27.4 \%)$, ignorance $(36.3 \%)$ and poverty (32.5\%) were the common barrier to seek ANC in the tea garden community. Bhattacherjee, S. et al.reported $81.2 \%$ of women were not aware of getting health done pre-or post-delivery and did not feel the necessity to go [10]. The other barriers in order of their frequency were distance of health center, financial constraints, family traditions and previous bad experiences [10]. In case of PNC we found, the main reason of not receiving PNC was lack of proper knowledge about it $(68 \%)$. In a study researcher found $94.6 \%$ cited the reason was lack of awareness, no postnatal visit by health workers and financial problems [10].

\section{CONCLUSION}

The present study revealed an unexpected low utilization of pregnancy related care among the study population. The use of ANC, INC and PNC are worse than national and regional level. The study highlights 
the barriers which hold back the participants from utilizing the services they needed during pregnancy, delivery and after delivery. The findings can assist the health mangers to identify the current state of utilization of pregnancy related care in tea garden community. It is very important to ensure focused antenatal care, delivery by skilled birth attendant and ideal four postnatal visitsin tea garden community. To promote ideal maternal health services utilization, there is need to formulate policies and design programs, which target women with low education, low income categories.

\section{REFERENCE}

1. Kabir R, Khan H. Utilization of Antenatal care among pregnant women of Urban Slums of Dhaka City, Bangladesh. IOSR Journal of Nursing and Health Science. 2013;2(2):15-9.

2. Laishram J, Mukhia S, Thounaojam UD, Devi HS, Panmei J. Knowledge and practice of antenatal care in an urban area.

3. De Bernis L, Sherratt DR, AbouZahr C, Van Lerberghe W. Skilled attendants for pregnancy, childbirth and postnatal care. British medical bulletin. 2003 Dec 1;67(1):39-57.

4. Islam MR, Odland JO. Determinants of antenatal and postnatal care visits among Indigenous people in Bangladesh: a study of the Mru Community. Rural Remote Health. 2011 Jun 28;11(2):1672.

5. World Health organization (WHO) 2013.

6. Pruthi N, Bacchani S, Singh V. Knowledge, attitude and practice regarding antenatal care among husbands attending antenatal clinic in a tertiary care hospital. International Journal Of Community Medicine And Public Health. 2016 Dec 28;3(7):1741-4.

7. World health organization (WHO). Antenatal care. Opportunities for Africa's newborn. pp. 5162. Retrieve from www.who.int/pmnch/media/ publications/aonsect ionIII_2

8. Rutaremwa G, Wandera SO, Jhamba T, Akiror E, Kiconco A. Determinants of maternal health services utilization in Uganda. BMC health services research. 2015 Dec;15(1):271.

9. Saikia S, Misra S, Misra B. Tea garden labours and their living conditions: a study on sarusarai tea garden of jorhat district of Assam. InXV Annual International Seminar On Economy, Enterprise and Employment 2014 (pp. 509-517).
10. Bhattacherjee S, Datta S, Saha JB, Chakraborty M. Maternal health care services utilization in tea gardens of Darjeeling, India. Journal of basic and clinical Reproductive Sciences. 2013;2(2):77-84.

11. Fronczak N, Arifeen SE, Moran AC, Caulfield LE, Baqui AH. Delivery practices of traditional birth attendants in Dhaka slums, Bangladesh. Journal of health, population, and nutrition. 2007 Dec;25(4):479.

12. Manna PK, De D GD. Knowledge, attitude and practices for antenatal care and delivery of the mothers of tea garden in Jalpaiguri and Darjeeling districts, West Bengal. National Journal of Community Medicine. 2011;2(1):4-8.

13. Bangladesh Demographic and Health Survey (BDHS 2014)

14. Ansari MM, Biswas SN, Hussain RF, Ripon SH, Hossain MN. Maternal and Newborn Health Care Practices in Rural Bangladesh. KYAMC Journal. 2017 Apr 24;5(1):453-7. 